\title{
Relationship between UV Energy and Formation of Secondary Particles in Santiago de Chile
}

\author{
Ernesto V. Gramsch ${ }^{1}$, Cristian R. Soto ${ }^{1}$, Pedro P. Oyola ${ }^{2}$, Felipe A. Reyes ${ }^{2}$, Yeanice Vasquez ${ }^{2}$, \\ María A. Rubio ${ }^{3}$, Patricio A. Pérez ${ }^{1}$, Matías Tagle ${ }^{2}$ \\ ${ }^{1}$ Physics Department, University of Santiago de Chile, Santiago, Chile \\ ${ }^{2}$ Mario Molina Center for Environmental Studies, Santiago, Chile \\ ${ }^{3}$ Facultad de Química y Biología and CEDENNA, Universidad de Santiago de Chile, Santiago, Chile
}

\begin{abstract}
Despite reduction efforts, the concentration of $\mathrm{PM}_{2.5}$ (particulate matter $\leq 2.5 \mu \mathrm{m}$ in diameter) has remained steady or even grown slightly in Santiago, Chile, over the last few years. However, this potential increase may be due to the formation of secondary particles rather than a rise in primary emissions. Therefore, this study measured the size distribution of particulate matter with an Electrical Low Pressure Impactor (ELPI; Dekati) to investigate the generation of secondary ultrafine particles at several sites in this metropolitan area during 2013 and 2018. Little formation was detected during winter, but more activity was observed during fall, and the highest generation of these particles was found during summer, when the number of new particles between 10 and $20 \mathrm{~nm}$ in diameter displayed an obvious peak in the afternoon during periods of high solar radiation. Overall, no clear relationship was discerned between the secondary particle number and the UV radiation until the latter exceeded $\sim 4.5 \mathrm{~kJ} \mathrm{~m}^{-2}$, when an almost linear correlation $\left(\mathrm{R}^{2}=0.739\right)$ appeared. Additionally, the particle number exhibited a much lower correlation with the total solar energy, indicating that UV solar radiation plays the major role in ultrafine particle formation. However, these trends may only apply to polluted cities, which already contain elevated particulate matter concentrations. Also, the fact that secondary formation primarily occurs in Santiago during summer, when the $\mathrm{PM}_{2.5}$ level is low, confirms that large numbers of pre-existing particles inhibit the creation of new ones.
\end{abstract}

Keywords: Ultrafine particles; New particle formation; UV radiation.

\section{INTRODUCTION}

The city of Santiago, Chile, is known to have very high $\mathrm{PM}_{2.5}$ and $\mathrm{PM}_{10}$ concentrations, especially during winter (Artaxo et al., 1999; Kavouras et al., 2001; Gramsch et al., 2006). The authority (CONAMA and Ministry of the Environment) has been trying for two decades to decrease particulate matter levels in the city. The results are encouraging, and there has been a decrease of $\mathrm{PM}_{10}$ and $\mathrm{PM}_{2.5}$ since 1998. However, a leveling off and even a small increase in $\mathrm{PM}_{2.5}$ has been observed in the last few years (Moreno 2010), pointing to the need for a more thorough study of the sources of this contamination (Dunn, 2004). One of the possible causes of this increase is new particle formation (NPF) which occurs via gas-phase processes (McMurry et al., 2000; Hallar et al., 2016; Kim et al., 2011). There are many factors affecting NPF, such as solar intensity;

\footnotetext{
* Corresponding author.

Tel.: 56-22718-1266; Fax: 56-22776-9596

E-mail address: egramsch@gmail.com
}

precursor gases, including $\mathrm{SO}_{2}, \mathrm{NO}_{x}$, and organics; and background aerosol concentration. Sulfuric acid $\left(\mathrm{H}_{2} \mathrm{SO}_{4}\right)$ has been named in many studies (McGraw and Zhang, 2008; Yue et al., 2010; Guo et al., 2020) as a very common precursor for NPF as well as volatile organic compounds, ammonia, and others. However, because atmospheric conditions in different cities are all very different, there are still uncertainties about a mechanism that consistently explain NPF (Gou et al., 2020). Santiago de Chile has low concentration of $\mathrm{SO}_{2}$ and ammonia (Sax et al., 2007), but high traffic density, and recently, photooxidation of vehicular exhaust, rather than $\mathrm{H}_{2} \mathrm{SO}_{4}$ or base species, has been proposed as dominant for NPF under urban conditions (Gou et al., 2020).

In a polluted city like Santiago, the large number of existing particles (Gramsch et al., 2009) offers a sizeable surface area that acts as a condensation sink where ultrafine particles coagulate rapidly, so new particle formation does not occur or cannot be detected (Guo et al., 2014; Birmili and Wiedensohler, 2000; Yue et al., 2010).

However, it is also known that events with new particle formation are not uniform over a city because they depend on several factors such as availability of precursor gases, solar radiation and concentration of existing particles before 
the event. The exact dependence of the formation of new particles on these parameters is not well known in a large city, so non-continuous measurements of particle number distribution were performed in year 2013 and 2018 at several sites in the city of Santiago or its surroundings with an ELPI monitor. Most measurements were performed for a short period of time (1-4 weeks) because the instrument was not available for longer intervals in each campaign. The total number of days with valid data was 131. A comparison of the UV and total solar energy with the ultrafine particles present in the sites allowed the extraction of information about the factors that influence new particle formation.

\section{EXPERIMENT}

\section{Sampling Sites and Measurement Periods $3 C V$ Site}

The Center for Vehicle Control and Certification (3CV) of Chile's Ministry of Transport and Telecommunications is located in the western part of Santiago, in a residential area, about $100 \mathrm{~m}$ north of a street with about 12,000 vehicles per day. The site is upwind from downtown Santiago; thus, it has little influence from pollution from other parts of the city. Measurements were performed with the ELPI from January 31 to February 2, 2013. Fig. 1(a) shows Santiago and the surrounding area; Fig. 1(b) shows the city with the location of all monitoring sites. The white arrow indicates the prevailing wind direction which occurs during the afternoon.

\section{Alameda Site}

This site is located on the curbside of the busiest street of Santiago. The ELPI was installed in a small shelter on the balcony of a three-story building on the north side of the street, which has an east-west direction. This site is located west of downtown Santiago. Alameda has segregated traffic lanes: Three of them are used exclusively for public transportation and two are used for all other vehicles. Alameda has a flow of $\sim 77,000$ vehicles per day. This site has commercial activity and many office buildings. Measurements were made from July 9 to 15, 2013.

\section{La Cisterna Site}

This site was located on the curbside of a large street, Gran Avenida, about $9 \mathrm{~km}$ south of downtown Santiago. This street has three lanes on each side with a high flux of small trucks, taxis, private vehicles, and several bus routes. During the campaign in La Cisterna, the vehicular flux was approximately 10,000 vehicles per day. There is a lot of commercial activity and several office buildings in this street. Measurements were made from July 12 until 23, 2013.

\section{Las Condes Site}

This is an urban site located in the eastern part of Santiago in the middle of a small park, at 700 meters above sea level (m.a.s.l.) and $100 \mathrm{~m}$ south of Las Condes Avenue. The area is primarily residential, with some retail stores located around the larger streets. The Las Condes station is known for being a receptor site for pollution coming from downtown Santiago (Koutrakis et al., 2005; Gramsch et al., 2006). Measurements were made from August 1 to 8, 2013, and between March 27 and May 21, 2018.

\section{USACH Site}

The sampling site is located in the middle of the campus of the Universidad de Santiago de Chile, about 500 m north of the main street (Alameda) and $200 \mathrm{~m}$ west of Matucana Street. Alameda was described above as the largest street in Santiago, with a flow of about 77,000 vehicles per day (Gramsch et al., 2013); Matucana is another large street with about 30,000 vehicles per day. The university campus is located approximately in the middle of the city, about $3 \mathrm{~km}$ west of downtown. The area has a lot of commercial and retail activity, but it is also a residential area. Because the
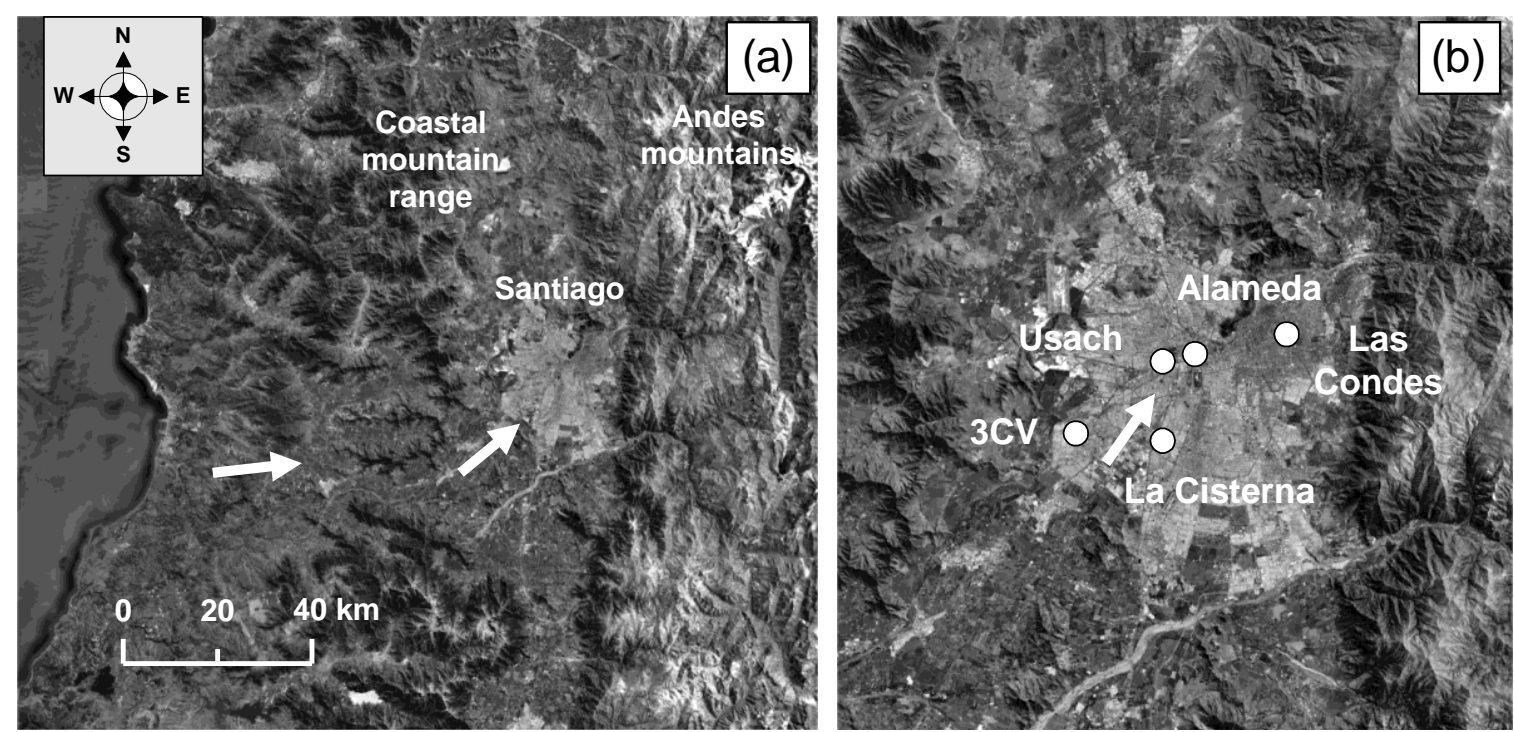

Fig. 1. (a) Extended map of Santiago de Chile, showing main route for incoming wind. (b) The city with the location of the monitoring sites. The arrows indicate the prevailing wind direction. 
site does not have direct influence from emission sources and it is located in the middle of the city, it can be considered as an urban background station. Measurements were made with the ELPI in the summer of 2013 (January 9-24) and in the winter of 2013 (May 10-June 18).

\section{Instruments}

The original design of the Electrical Low Pressure Impactor (ELPI; Dekati, Tampere, Finland) was published by Keskinen et al. (1992). The instrument is composed of several impactors covering the size range of $10,21,39,72$, 120, 201, 314, 480, 757, 1224, 1945, 3074, 5134 and 8087 $\mathrm{nm}$. Each impactor is also connected to an electrometer that measures the charge deposited with each particle trapped in the plate. Knowing the charging efficiency, in principle it is possible to know the number of particles deposited in each stage. The ELPI was used to measure particle number at several urban background and curbside sites in Santiago. A complete description of the instrument and its calibration are published elsewhere (Marjamäki et al., 1999; Matti et al., 2000; Ouf and Sillon, 2009; Järvinen et al., 2014).

Meteorological parameters (wind direction and speed, temperature, humidity, pressure, and rain) were measured at the Physics Department of the Universidad de Santiago with a NovaLynx Weather Station. Solar radiation was measured with a sensor built at the university, consisting of a silicon detector coupled to an operational amplifier enclosed in an aluminum housing. The sensor was calibrated against a Kipp \& Zonen CMP22 pyranometer. Ultraviolet radiation (erythemally weighted UV-B) was measured with a Solar Light Co. PMA2101 detector calibrated at the factory. The UV detector's response follows closely the erythemal action spectrum (McKinlay and Diffey, 1987), which is used because it has the largest immediate short-term impact on humans. Thus, the spectral response of the detector has a higher weighting factor between 280 and $300 \mathrm{~nm}$ and decreases quickly toward $400 \mathrm{~nm}$ (Fioletov et al., 2010).

\section{Data Analysis}

There are various criteria for determining new particle formation events. A common visual approach is the identification of a "banana" shape (Dal Maso et al., 2005; Heintzenberg et al., 2007) in a 2D plot of particle diameter versus time. For instance, the criteria used by Dal Maso et al. (2005) was: "1) A distinctly new mode of particles must appear in the size distribution. 2) The mode must start in the nucleation mode size range. 3) The mode must prevail over a time span of hours. 4) The new mode must show signs of growth." These criteria were used in regional events in order to exclude new particle formation from anthropogenic primary sources. It was justified by the need to separate local pollution sources, such as traffic, heating, or industrial emissions, which are also capable of generating nano-sized particles. Local pollution sources are very pertinent in a city, because vehicles generate large amounts of ultrafine particles (Wahlin et al., 2001; Gidhagen et al., 2005; Monkkönen et al., 2005; Lin et al., 2015) all over the city. Heating and industrial sources also generate large amounts of ultrafine particles. This method may not work well in cities like
Santiago, which is highly polluted, but the surroundings are clean. The prevailing wind comes from the west, which is mostly rural and from the Pacific Ocean, which is located less than $90 \mathrm{~km}$ from the city. If the wind is strong enough, it brings clean air from the ocean, removes the newly formed particles and no growth can be seen. In this case, only the burst of nucleation-mode particles is seen, but not the evolution in time.

An alternative approach that can be used to separate primary nucleation-mode particles (generated by anthropogenic sources) from secondary nucleation-mode particles (generated in the atmosphere from gaseous precursors) is to look at the temporal profile of the particles. A very similar approach has been used to identify NPF events in Budapest and other central European cities by calculating the nucleation strength factor (NSF) (Salma et al., 2014; Salma et al., 2017; Nemeth et al., 2018). Primary nucleation-mode particles generated by vehicles, heating, or industrial sources have a distinct temporal profile, and in Santiago it has been well studied before (Jorquera et al., 2004; Gramsch et al., 2009; Pérez and Gramsch, 2016). Fig. 2 shows typical ultrafine particle profiles of anthropogenic origin in Santiago for an urban curbside site in winter (a) and a background site in fall (b). The curbside site has strong influence from vehicles and a pronounced ultrafine particle peak is seen during the morning rush hour ( 8 a.m.). This peak is almost exclusively due to vehicular emissions of nucleation-mode particles. At this time of day there is very little wind (Gramsch et al., 2006; Muñoz and Corral, 2017) and high particle accumulation. A smaller peak is seen in Fig. 2(a) during the evening rush hour because the traffic is more spread out in time and the wind speed is higher, dispersing the pollutants. In most cities, large streets are usually far from residential areas, and receive less influence from residential sources than urban background sites; such is the case for La Cisterna. The urban background site (Fig. 2.(b)) also shows high concentration of ultrafine particles during the morning and evening rush hours, but the peak around 8 p.m. is larger than the peak at the curbside site. This is most likely related to residential emissions because the USACH site is closer to a residential area. The decrease in ultrafine particle concentration during the afternoon at both sites is due to an increase in wind speed that brings clean air to the area.

Ultrafine secondary particles are formed when precursor gases and UV radiation are available to start the reaction (Seinfeld and Pandis, 2006, and references therein; Sorribas et al., 2015; Hallar et al., 2016). Most of the reactions leading to new particle formation are triggered by UV-A radiation (320-400 nm) (Seinfeld and Pandis, 2006, and references therein). In this work, measurements were performed with an erythemally weighted UV-B detector which includes a small fraction of UV-A, but both UV bands are closely related and variations in both bands are very similar. However, a large amount of pre-existing particles can suppress aerosol nucleation by scavenging newly nucleated particles. Santiago and many large polluted cities (Kulmala et al., 2004; Gramsch et al., 2009; Kumar et al., 2014) have very high background accumulation-mode particle concentrations that act as condensation sinks. The concentration of these particles is 

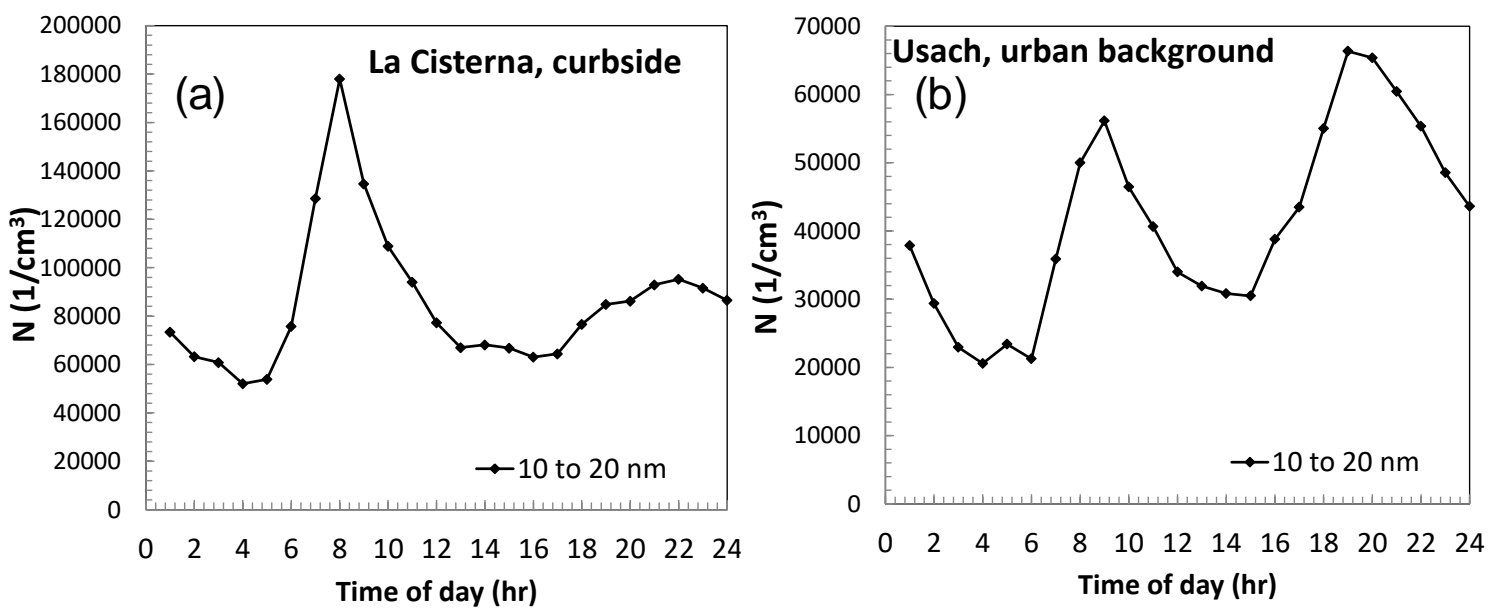

Fig. 2. (a) Average number concentration for 10-20-nm diameter particles at a curbside site in Santiago (La Cisterna; July 18-29, 2013). (b) Average number concentration at an urban background site (USACH; May 10-June 18, 2013).

generally higher for cities in developing countries (Dall'Osto $e t$ al., 2011), and new particle formation events are hard to observe. Nevertheless, it is still possible to observe many new particle formation events under specific circumstances. In most previous work, frequent new particle formation events were observed in spring (Wu et al., 2007; Sorribas et al., 2015). A long-term study in a clean site by Hallar et al. (2016) found that the maximum of new particle formation occurs in spring, but there are also frequent NPF events during the remainder of the year. In Santiago, which is a polluted city, the highest frequency of new particle formation events was observed in summer, with very few NPF events during winter. As mentioned before, it seems that NPF events in Santiago are constrained to the city; thus, new particles are not formed in the rural areas around the city as observed in other studies (Dal Maso et al., 2005; Sorribas et al., 2015; Hallar et al., 2016). The assumption is based on: 1) The "banana" shape (Dal Maso et al., 2005; Heintzenberg et al., 2007) cannot be seen in any of the particle number distribution plots (Fig. 3). 2) During the afternoon, the wind comes from the west, which is a rural area sparsely populated and from the Pacific Ocean which is less than $90 \mathrm{~km}$ away. The wind removes the newly formed particles, and growth cannot be observed. 3) Santiago is a polluted city with many existing particles that may prevent growth of particles.

In this work, an approach very similar to what was used by Salma et al. (2014) was used. In order to distinguish NPF events in Santiago, the time series of the nucleation-mode particles (10-20 nm) has been plotted and the deviation from the typical shape (Figs. 2(a) and 2(b)) during the hours of high solar radiation has been used to identify a new particle formation event. A peak between 2 and 5 p.m. in the nucleation plot indicates the formation of new particles. A clear example of an NPF event is shown in Fig. 3. The plot shows the combined 10- and 21-nm diameter particles from the ELPI for January 9, 2013, in USACH. The plot shows a peak of ultrafine particles during morning rush hour (around 8 a.m.) which is related to vehicular emissions. Later on, the number of particles decreases, but at 12 a.m. there is a remarkable increase which departs from the typical shape for Santiago. This peak approximately coincides with the maximum solar radiation, and indicates new particle formation due to photochemical processes. Later in the afternoon the peak decreases, most likely because the wind brings clean air into the area and disperses the particles. The predominant wind direction is shown with a white arrow in Fig. 1(b). Because of this wind, which is typical of Santiago, it is not possible to observe the growth of particles for this event. Fig. 3(b) also shows that particle growth cannot be observed because the characteristic "banana" shape (Heintzenberg et $a l ., 2007$ ) is not seen. To obtain the number of new secondary particles a calculation was made for each event, by adding the particles under the afternoon peak and subtracting the background (indicated with a shaded polygon in Fig. 3(a). A computer algorithm was written to calculate the number of new secondary particles by adding the number of particles between 12 and 5 p.m. The algorithm also calculates the average between 10 and 12 a.m. and the average between 5 and 6 p.m., which are used to subtract the background. These calculations were made for all the available data. When the calculation gave a negative value, zero was recorded. Negative numbers occur when the number of particles between 10 and 12 a.m. or between 5 and 6 p.m. are larger than the number of particles between 12 and 5 p.m. This situation most likely occurs when no secondary particles are formed. The background-subtraction method is commonly used in atomic and nuclear spectroscopy (Knoll, 2010).

In order to compare with previous studies (Salma et al., 2014; Salma et al., 2017; Nemeth et al., 2018), the nucleation strength factor was calculated for all measurement periods. The NSF is defined as:

$$
N S F=\frac{\left(\frac{N_{10-100}}{N_{100-1000}}\right)_{\text {nucleation days }}}{\left(\frac{N_{10-100}}{N_{100-1000}}\right)_{\text {non-nucleation days }}}
$$

$\mathrm{PM}_{2.5 \mathrm{D}}=(\mathrm{S}-\mathrm{L}) \mathrm{f}_{1}+\mathrm{Lf}_{2}$ 

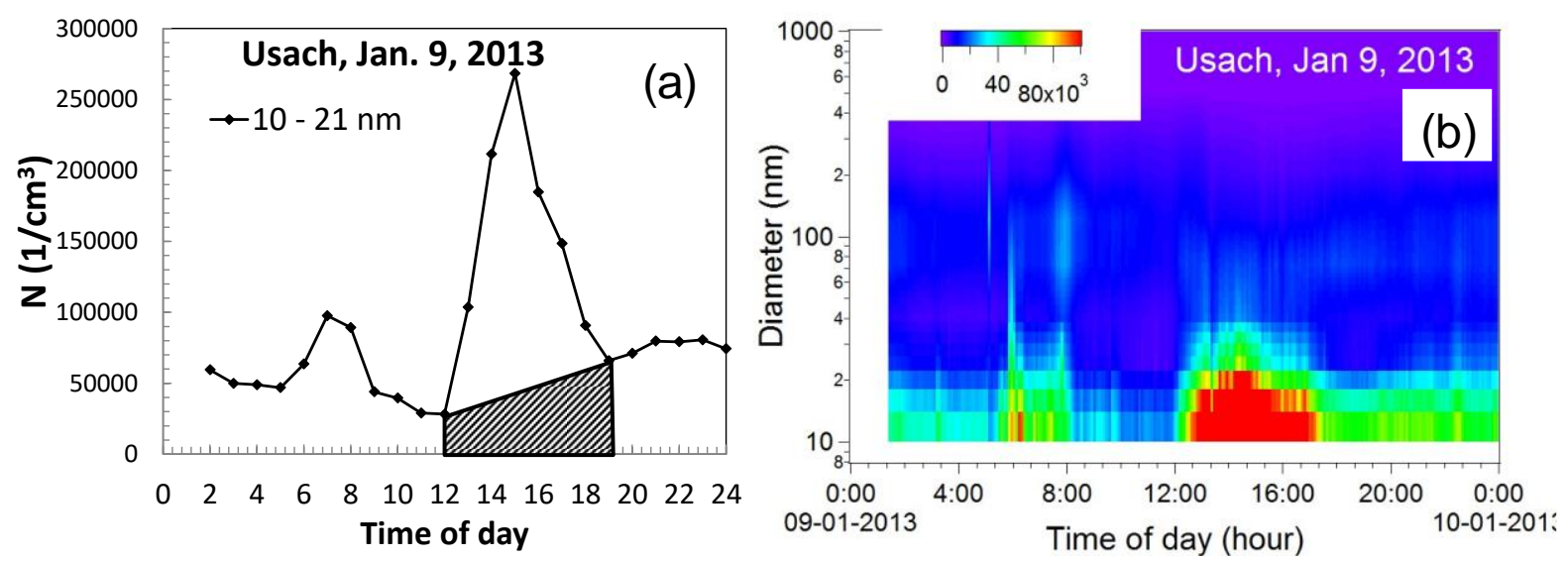

Fig. 3. (a) Particle number concentration for a day with a strong NPF event at USACH for the 10- and 21-nm diameter particles. (b) 2D plot of the same event.

The NSF factor takes into account the increment in the number of ultrafine particles (Aitken and nucleation mode) with respect to accumulation- and condensation-mode particles and normalizes for non-nucleation days. This factor allows subtracting increases in ultrafine particles that are not related to secondary particle formation. Classification of days with and without nucleation was performed using the algorithm suggested by Salma et al. (2014). The results are shown in Table 2 and discussed in the next section.

\section{RESULTS}

Several campaigns were performed in all seasons at the eight sites in Santiago in 2013 and 2018. Table 1 shows the sampling sites, measurement dates, as well as the season. An inter-comparison is presented between the stations and dates to show the pollution characteristics of the sites.

\section{Size Distribution}

The average particle size distribution in winter and fall for years 2013 and 2018 for each period, is presented in Fig. 4. for Alameda, Las, Condes, La Cisterna and USACH. The measurement period is shown in Table 1.

The largest number of particles is seen in Alameda and La Cisterna and the shape is also similar, which can be explained because both are large streets with many bus services using them and a high vehicular flux. The maximum in the particle number is at $10 \mathrm{~nm}$, which is expected, because vehicles generate large number of ultrafine particles. Measurements in Las Condes and USACH show lower particle number and a slightly different shape than the previous sites. The total number of particles is lower because they have less ultrafine particles, but at larger sizes all curves tend to match. For these sites there is a second maximum around $100 \mathrm{~nm}$. This difference shows the appearance of the accumulation mode in Las Condes and USACH which is not clearly seen in Alameda and La Cisterna. Alameda and La Cisterna are curbside sites with strong influence of ultrafine particles from traffic (Whalin et al., 2001); Las Condes is a receptor site, with particles arriving from downtown which are larger because they have grown by coagulation and condensation
(Gramsch et al., 2009). The particle size distribution at USACH (Fig. 4) during fall also has a shape which is typical of a receptor site. The size distribution has a secondary peak toward larger particles $(\sim 100 \mathrm{~nm})$. These particles could be generated by coagulation and agglomeration of smaller particles generated near the streets or by other processes, such as wood combustion in fall, because the USACH site is closer to residential areas. During summer, the shape distribution at USACH does not show the secondary peak, probably because there is no influence from wood burning. The plot shows that there are fewer large particles in summer than in winter, which is consistent with improved dispersion in Santiago (Koutrakis et al., 2005). But, at USACH, for smaller particles, the trend is reversed, and the number of smaller particles in summer is greater than in winter. This is probably an indication that the generation of secondary ultrafine particles is much higher in summer than in winter.

\section{New Particle Formation and Radiation}

NPF events have been observed at several places and years, mostly on days with high solar irradiance and clean environments (Dunn et al., 2004; Kulmala et al., 2004; Sorribas et al., 2015). Gramsch et al. (2014) show that in clean environments NPF events are clearly seen when solar irradiation is high, and little formation is seen when solar radiation is low, or there is a high load of primary particles. Inhibition of NPF events has been seen in other studies (Dunn et al., 20041 Kulmala et al., 2004). In the present work, no new ultrafine particle events were found on the curbside sites (Alameda, La Cisterna).

In the urban USACH site, measurements were made in the summer of 2013, from January 9-24. This is a background site, located far from the direct influence of emissions sources, but because it is located in the middle of the city the particle load is high. In all days, clear peaks in the ultrafine particle number profile were observed between 12 and 6 p.m. As before, these peaks occur at about the same time when solar radiation reaches its maximum. Winter measurements were also made at the USACH site from May 10-June 18, 2013. In this campaign there was only 1 day in which a clear ultrafine secondary peak was observed. In the $3 \mathrm{CV}$ and Las 
Table 1. Sampling sites and dates.

\begin{tabular}{llllll}
\hline$\#$ & Sampling site & Type & Start date & End date & Season \\
\hline 1 & 3CV & Urban backgd. & Jan. 31, 2013 & Feb. 5, 2013 & Summer \\
2 & Alameda & Urban curbside & July 9, 2013 & July 15, 2013 & Winter \\
3 & La Cisterna & Urban curbside & July 12, 2013 & July 23, 2013 & Winter \\
4 & Las Condes & Urban backgd. & Aug. 1, 2013 & Aug. 6, 2013 & Winter \\
5 & Las Condes & Urban backgd. & Mar. 28, 2018 & May 21, 2018 & Fall \\
6 & USACH & Urban backgd. & Jan. 9, 2013 & Jan. 24, 2013 & Summer \\
7 & USACH & Urban backgd. & May 10, 2013 & June 17, 2013 & Fall \\
\hline
\end{tabular}

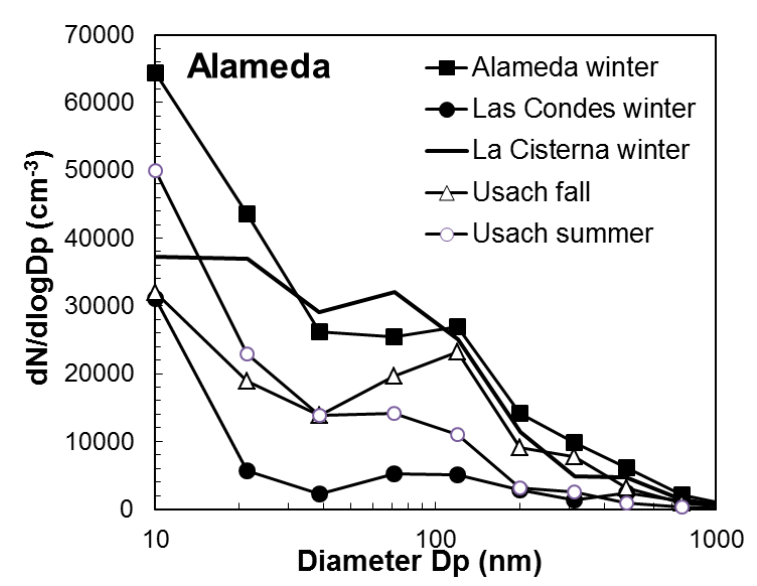

Fig. 4. Average particle size distribution in Alameda for the month of July, La Cisterna for July, Las Condes for August, and USACH for January and August. Campaign dates are summarized in Table 1.

Condes sites, which are also located far from large streets and measurements were performed in summer, many ultrafine particles were detected.

To illustrate the relationship between ultrafine particle formation and solar radiation, the UV-B total daily energy for 2013 and the net number of secondary ultrafine particles at all sites and all years were plotted in Fig. 5. The number of days with NPF events was 35 out of 131 days with valid data. As explained in the "Data analysis" section, the number of new particles between 10 and $20 \mathrm{~nm}$ has been calculated using the integral of the afternoon peak (Fig. 3(a)) and when the net number was negative, it was replaced with 0 . Fig. 5 shows that when UV energy is high the number of new particles is high, and vice versa. Although UV radiation is only that of 2013 and the particles are from 2013 and 2018, the UV profile does not change from one year to another and can be used to make a qualitative comparison. The plot shows that in Santiago new secondary particles are formed mainly in summer. To study if there is a relationship between solar energy and new ultrafine particle formation, a correlation plot has been calculated between these variables for all the data. Fig. 6(a) shows the net number of new particles from 10 to $20 \mathrm{~nm}$ versus the total UV-B energy during the day. The plot has data for two years (2013 and 2018) and three sites (Las Condes, USACH and 3CV) and each point represent one day with UV energy and number of particles for that day. Two trends can be seen in the plot: For energies below $\sim 4.5 \mathrm{~kJ} \mathrm{~m}^{-2}$ there is no clear relationship between new

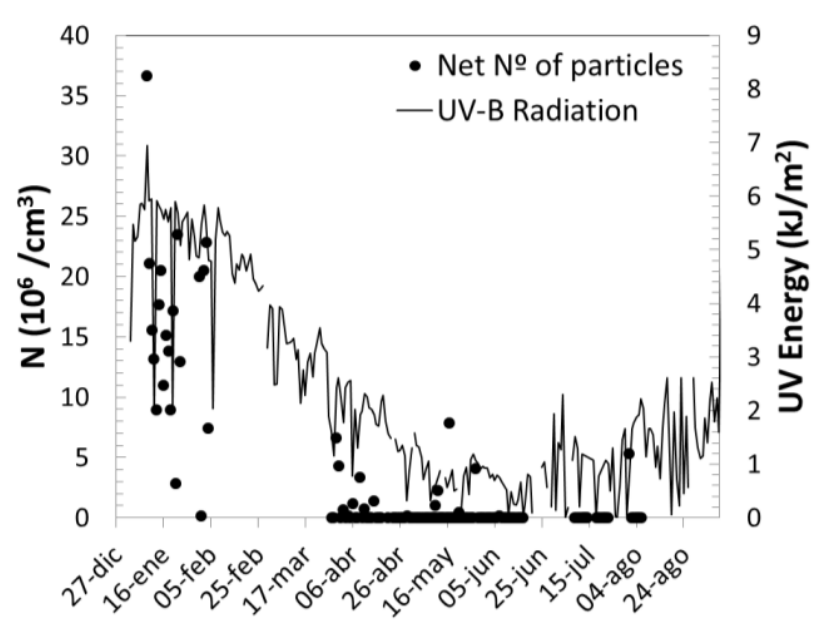

Fig. 5. Net number of ultrafine particles (10-20 nm) between 12 and 5 p.m. at all sites and UV-B energy for 2013.

particle formation and energy, and the number of particles is lower than $\sim 10^{6} \mathrm{~cm}^{-3}$. For energies greater than $\sim 4.5 \mathrm{~kJ} \mathrm{~m}^{-2}$, there is almost a linear relationship between the number of new particles and UV-B energy, with a correlation coefficient of $\mathrm{R}^{2}=0.739$. Because the data was measured in two different periods and two different sites in Santiago, the almost linear relationship indicates that NPF depends mostly on the intensity of UV-B radiation and not so much on the site.

In order to show that the increase between 12 and 5 p.m. is indeed due to the influence of UV radiation on formation of new particles, the same type of calculation was performed with particles from 38-71 nm and 120-313 nm. Figs. 6(b) an 6(c) show the net number of particles versus UV energy. For $38-71 \mathrm{~nm}$, the net number of particles decrease for all UV energies but there is still some correlation $\left(R^{2}=0.264\right)$ between UV and number of particles for energies larger than $\sim 4.5 \mathrm{~kJ} \mathrm{~m}^{-2}$. For 120-313-nm-sized particles, there is no correlation with UV energy. If the total number of particles, without background subtracting, is plotted against UV radiation, a figure similar to Fig. $6(\mathrm{c})$ is obtained. In this case the correlation between number of particles and UV radiation greater than $4.5 \mathrm{~kJ} \mathrm{~m}^{-2}$ is $\mathrm{R}^{2}=0.661$. The total number of particles is dominated by the small particles; thus, the correlation is almost as high as the correlation with the 10-20-nm group of particles.

To examine the influence of wind on the formation of new particles, data on wind speed and direction has been collected for the days with UV energy greater than $\sim 4.5 \mathrm{~kJ} \mathrm{~m}^{-2}$ in Fig. 6(a). The maximum wind speed for each day fluctuated 

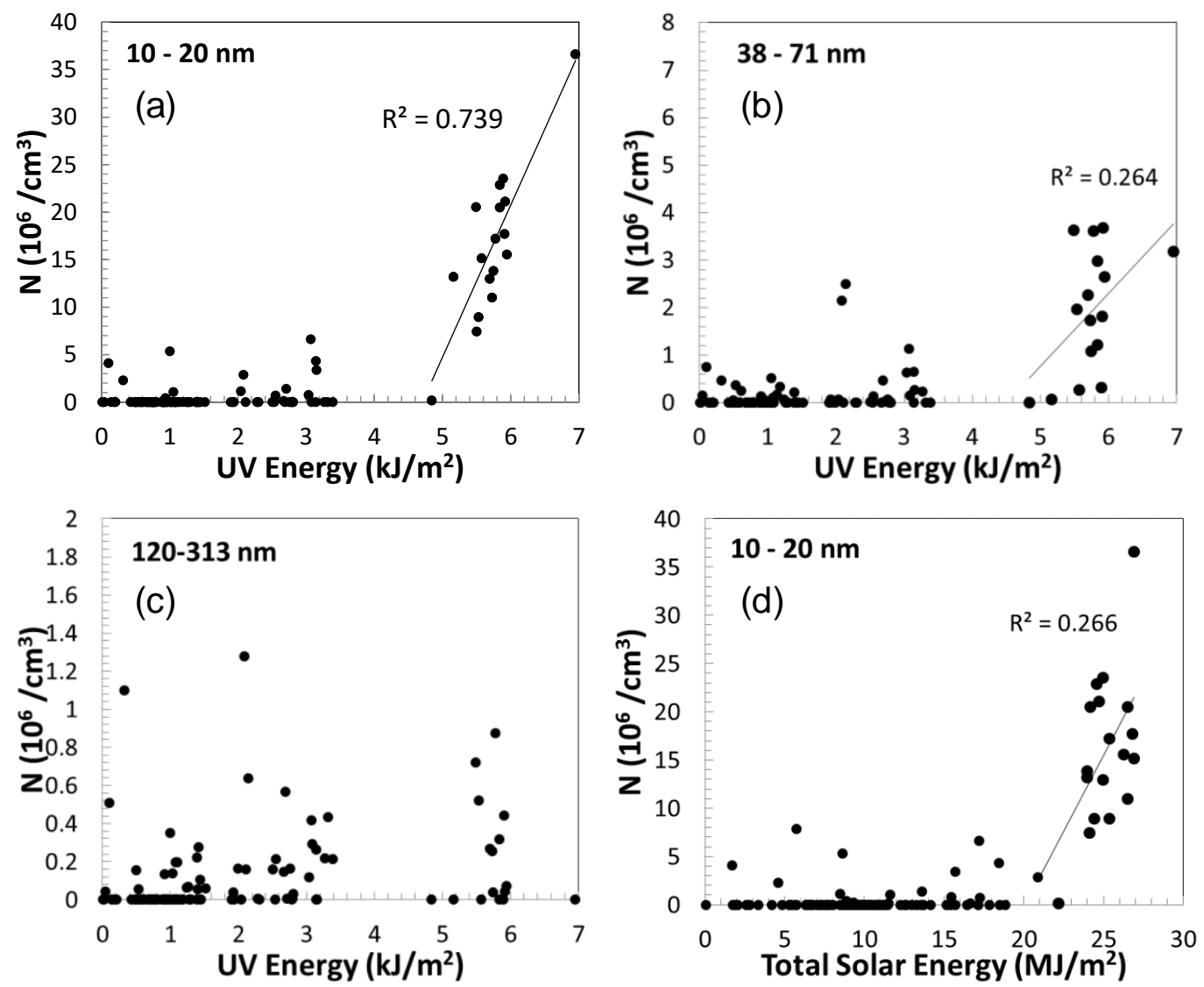

Fig. 6. Correlation between the net number of (a) 10-20-nm, (b) 38-71-nm, and (c) 120-313-nm particles. (d) Correlation between the total solar energy and net number of 10-20-nm particles.

between 2.7 and $3.7 \mathrm{~m} \mathrm{~s}^{-1}$. The wind direction for each day fluctuated between 208 and $230^{\circ}$ between the hours 12:00 and 3:00 p.m. This direction is indicated with an arrow in Fig. 1(b). Because the wind that enters the city comes from the Pacific Ocean or rural areas to the west of the city, clean air with few particles and low concentration of precursor gases reaches the measuring site removing the newly formed particles.

The same analysis has been made in Fig. 6(d) for total solar energy. Below $\sim 20 \mathrm{MJ} \mathrm{m}^{-2}$ there is no clear trend between the solar energy and number of new particles, but above this energy there is an increase in the number of particles when the energy increases. However, the correlation between these variables is low $\left(\mathrm{R}^{2}=0.265\right)$. These data give an indication that UV-B solar radiation, rather than total solar energy, plays a role in the formation of new ultrafine particles. In addition, the correlation plots show that to have a noticeable relationship between the formation of new particles and UV-B radiation, the energy has to be greater than $\sim 4.5 \mathrm{~kJ} \mathrm{~m}^{-2}$. This behavior may have several origins: type and amount of precursor gases, background aerosol concentration, and solar radiation. Moreover, this two-trend characteristic may only exist in large cities, not in clean, rural sites (Sorribas et al., 2015, and references therein; Hallar et al., 2016). It has to be noted that a correlation between UV energy and new particle formation is expected, but the role that precursor gases and pre-existing particles play changes from place to place and from one season to another. So, in general, there is no clear relationship between NPF and UV radiation. We only observed a linear relationship in summer.

As shown in Fig. 5, formation of large numbers of new particles occurs when solar UV radiation is high, which corresponds to the summer season. Also, high pollution levels in Santiago occur in winter $\left(\mathrm{PM}_{2.5}\right.$ is almost 3 times higher in winter than in summer; Koutrakis et al., 2005), so new particle formation from precursor gases has little influence on the high pollution levels seen in Santiago.

\section{Nucleation Strength Factor}

As mentioned in the "Experiment" section, NSF was calculated for all measurement periods, using the modified algorithm suggested by Salma et al. (2014). The days with and without new particle formation were selected using a 2D plot similar to Fig. 3(b). Subsequently the NSF is calculated using Eq. (1) and Salma's et al. algorithm. Table 2 shows the calculated NSF for all measurement periods. The NSF has to be calculated using nucleation and non-nucleation days for the period. In this study, there were several sites that had only nucleation days or only non-nucleation days, as shown in Table 2; thus, the NSF could only be calculated for two periods, which is a limitation of this method. Fig. 7 shows the calculated NSF plot for two sites along with the average number of non-nucleation days and the number of 
Table 2. Number of nucleation and non-nucleation days and NSF for all sites and dates.

\begin{tabular}{lllllll}
\hline \# & Sampling site & Season & Total \# of days & \# of nucleation days & \# of non-nucleation days & NSF \\
\hline 1 & 3CV & Summer & 5 & 5 & 0 & \\
6 & Alameda & Winter & 6 & 0 & 6 & \\
9 & La Cisterna & Winter & 8 & 0 & 8 & \\
11 & Las Condes & Winter & 7 & 0 & 7 & 1.159 \\
12 & Las Condes & Fall & 51 & 10 & 41 & \\
17 & USACH & Summer & 15 & 15 & 0 & 1.063 \\
18 & USACH & Fall & 39 & 5 & 34 & \\
\hline
\end{tabular}
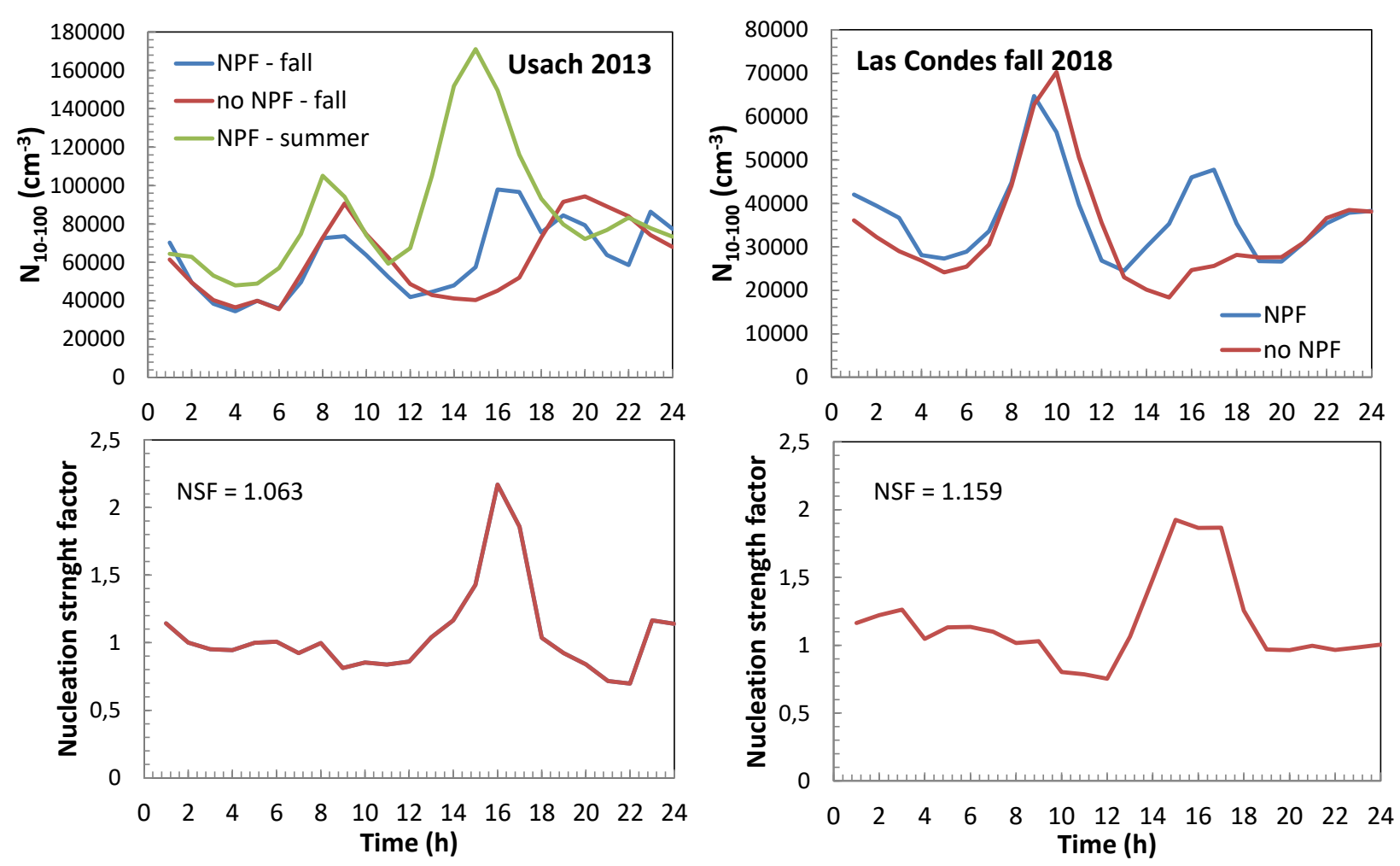

Fig. 7. Diurnal variation of the number of particles during NPF and non-NPF days (top panel) and NSF for the same periods (bottom panel).

nucleation days in both sites. According to Nemeth et al. (2018), when NSF is greater than 1 but less than 2, it indicates that new particle formation has similar importance as the other sources in the city. When the NSF is greater than 2, NPF is the main contributor to ultrafine particles and when NSF is less than 1, the contribution of NPF to the total number of ultrafine particles is negligible. In this work, the NSF is slightly greater than 1 for both sites, and very similar to what was obtained by Nemeth et al. (2018) in Vienna. This can be explained because the measurements were made in the fall, which is a period where the UV radiation is not as high as in the summer and there are sources like wood burning that are not present in summer. It has to be noted also that the number of particles in Santiago is about 10 times higher than in Vienna (Nemeth et al., 2018). For comparison, Fig. 7 also shows the NPF in summer 2018, which is about 2 times higher than in fall. The plot in Fig. 7 indicates that the maximum in NPF occurs at $\sim 4$ p.m., i.e., 3 hours after the maximum in the solar radiation and at a time when $\mathrm{PM}_{2.5}$ is lowest. In addition, in most sites measurements were performed for a short period of time (Table 2); thus, the variability was high. During summer periods, in which the NSF is expected to be high, it could not be calculated because there were no days without nucleation.

Influence of Existing Particles on New Particle Formation In polluted environments like large cities, precursor gases form new particle clusters but they cannot survive because they rapidly condense into the surface of existing particles (Zhang et al., 2011), while in less polluted places, precursor gases condense into new particles. Several studies (Jayaratne et al., 2015; Hallar et al., 2016) have shown that new particle formation is more likely to occur at times and places with low background aerosol concentration. In the present study the number of pre-existing particles has been obtained by adding the particles between the hours of 10 and 12 a.m. for each event. Three groups were obtained, 20-100 nm, 100$300 \mathrm{~nm}$, and $300-700 \mathrm{~nm}$. A plot of the number of new 


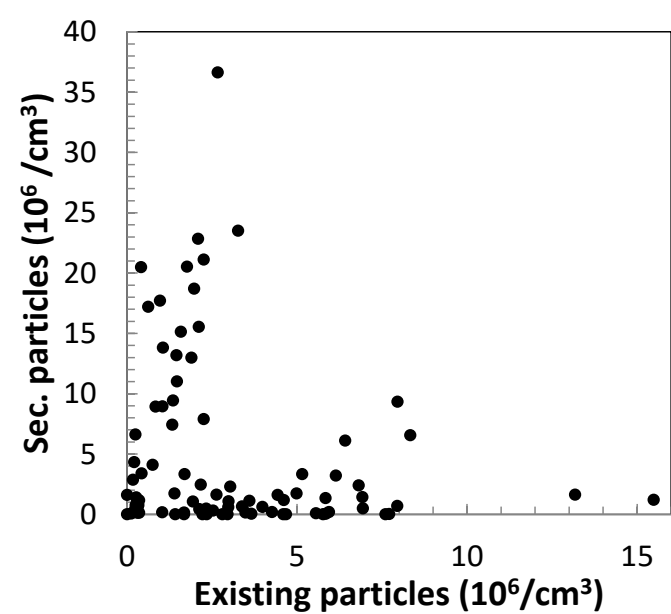

Fig. 8. Number of new particles (10-20 nm) at all sites versus the number of pre-existing large particles $(100-300 \mathrm{~nm})$.

particles versus the number of pre-existing particles from $100-300 \mathrm{~nm}$ is shown in Fig. 8. In order not to bias the plot, when the net number of particles was negative, the point was removed from the graph. It can be seen that formation of new particles is inhibited when there is a large number of pre-existing particles, although there is no clear relationship between these variables.

\section{CONCLUSIONS}

Evidence of new particle formation was noted at several sites in Santiago, Chile, on days with high solar radiation, mostly during summer. A strong correlation $\left(\mathrm{R}^{2}=0.739\right)$ was observed between the level of UV-B radiation and the number of secondary 10-20-nm-sized particles but only when the former exceeded $\sim 4.5 \mathrm{~kJ} \mathrm{~m}^{-2}$; below this value, no relationship was found. The UV radiation also showed a weaker correlation - or none at all-with larger particles. Moreover, the low correlation $\left(\mathrm{R}^{2}=0.265\right)$ between NPF and the total solar energy when the latter exceeded $\sim 20 \mathrm{MJ} \mathrm{m}^{-2}$ suggests that UV-B solar radiation is a larger factor in the generation of ultrafine particles. The trends we describe, however, may apply only to cities with large amounts of primary ultrafine particles, not to rural background sites with clean air. Because secondary formation for this size fraction mainly occurs during summer in Santiago, when the total $\mathrm{PM}_{2.5}$ concentration is low, the increase in overall pollution is probably unrelated to NPF. Our results demonstrate that the secondary generation of particles is inhibited by an abundance of pre-existing ones.

\section{ACKNOWLEDGEMENTS}

This study was funded by Fondecyt Project 1151117. Additional funding was provided by CEDENNA USACH Code AFB 18000-1 and Fondecyt Project 1170456.

\section{REFERENCES}

Artaxo, P., Oyola, P. and Martínez, R. (1999). Aerosol
Composition and Source Apportionment in Santiago de Chile. Nucl. Instrum. Methods Phys. Res., Sect. B 150: 409416. https://doi.org/10.1016/S0168-583X(98)01078-7

Birmili, W. and Wiedensohler, A. (2000). New particle formation in the continental boundary layer: Meteorological and gas phase parameter influence. Geophys. Res. Lett. 27: 3325-3328. https://doi.org/10.1029/1999GL011221

Dal Maso, M., Kulmala, M., Riipinen, I., Wagner, R., Hussein, T., Aalso, P.P. and Lehtinen, K.E.J. (2005). Formation and growth of fresh atmospheric aerosols: Eight years of aerosol size distribution data from SMEAR II, Hyytiälä, Finland. Boreal Environ. Res. 10: 323-336.

Dall'Osto, M., Thorpe, A., Beddows, D.C.S., Harrison, R. M., Barlow, J.F., Dunbar, T., Williams, P.I. and Coe, H. (2011). Remarkable dynamics of nanoparticles in the urban atmosphere. Atmos. Chem. Phys. 11: 6623-6637. https://doi.org/10.5194/acp-11-6623-2011

Dunn, M.J., Jimenez, J.L., Baumgardner, D., Castro, T., McMurry, P.H. and Smith, J.N. (2004). Measurements of Mexico City nanoparticle size distributions: Observations of new particle formation and growth, J. Geophys. Lett. 31: L10102. https://doi.org/10.1029/2004GL019483

Fioletov, V., Kerr, J.B. and Fergusson, A. (2010). The UV index: Definition, distribution and factors affecting it. Can. J. Public Health 101: I5-I9. https://doi.org/10.1007/ BF03405303

Gidhagen, L., Johansson, C., Langner, J. and Foltescu, V.L. (2005). Urban scale modeling of particle number concentration in Stockholm. Atmos. Environ. 39: 17111725. https://doi.org/10.1016/j.atmosenv.2004.11.042

Gramsch, E., Cereceda-Balic, F., Ormeño, I., Palma, G. and Oyola, P. (2004). Use of the light absorption coefficient to monitor elemental carbon and $\mathrm{PM}_{2.5}$. Example of Santiago de Chile. J. Air Waste Manage. Assoc. 54: 799808. https://doi.org/10.1080/10473289.2004.10470956

Gramsch, E., Cereceda-Balic, F., Oyola, P. and Von Baer, D. (2006). Examination of pollution trends in Santiago de Chile with cluster analysis of $\mathrm{PM}_{10}$ and Ozone data. Atmos. Environ. 40: 5464-5475. https://doi.org/10.1016/ j.atmosenv.2006.03.062

Gramsch, E., Gidhagen, L., Wahlin, P., Oyola, P. and Moreno, F. (2009). Predominance of soot-mode ultrafine particles in Santiago de Chile: Possible sources. Atmos. Environ. 43: 2260-2267. https://doi.org/10.1016/j.atmose nv.2009.01.047

Gramsch, E., Le Nir, G., Araya, M., Rubio, M.A., Moreno, F. and Oyola, P. (2013). Influence of large changes in public transportation (Transantiago) on the black carbon pollution near streets. Atmos. Environ. 65: 153-163. https://doi.org/10.1016/j.atmosenv.2012.10.006

Gramsch, E., Reyes, F., Oyola, P., Rubio, M. A., López, G., Pérez, P. and Martínez, R. (2014). Particle size distribution and its relationship to black carbon in two urban and one rural site in Santiago de Chile. J. Air Waste Manage. Assoc. 64: 785-796. https://doi.org/10.1080/10962247.2 014.890141

Guo, S., Hu, M., Peng, J., Wu, Z., Zamora, M. L., Shang, D., Du, Z., Zheng, J., Fang, X., Tang, R., Wu, Y., Zeng, L., Shuai, S., Zhang, W., Wang, Y., Ji, Y., Li, Y., Zhang, A. 
L., Wang, W., ... Zhang, R. (2020). Remarkable nucleation and growth of ultrafine particles from vehicular exhaust. Proceedings of the PNAS 117: 3427 3432. https://doi.org/10.1073/pnas.1916366117

Hallar, A.G., Petersen, R., McCubbin, I.B., Lowenthal, D., Lee, S., Andrews, E. and Yu, F. (2016). Climatology of new particle formation and corresponding precursors at storm peak laboratory. Aerosol Air Qual. Res. 16: 816826. https://doi.org/10.4209/aaqr.2015.05.0341

Heintzenberg, J., Wehner, B. and Birmili, W. (2007). How to find bananas in the atmospheric aerosol: new approach for analyzing atmospheric nucleation and growth events. Tellus B 59: 273-282. https://doi.org/10.1111/j.16000889.2007.00249.x

Järvinen, A., Aitomaa, M., Rostedt, A., Keskinen, J. and YliOjanperä, J. (2014). Calibration of the new electrical low pressure impactor (ELPI+). J. Aerosol Sci. 69: 150-159. https://doi.org/10.1016/j.jaerosci.2013.12.006

Jayaratne, E.R., Clifford, S. and Morawska, L. (2015). Atmospheric visibility and $\mathrm{PM}_{10}$ as indicators of new particle formation in an urban environment. Environ. Sci. Technol. 49: 12751-12757. https://doi.org/10.1021/acs.es t.5b01851

Jorquera, H., Orrego, G., Castro, J. and Vesovic, V. (2004). Trends in air quality and population exposure in Santiago, Chile, 1989-2001. Int. J. Environ. Pollut. 22: 507-530. https://doi.org/10.1504/IJEP.2004.005684

Kavouras, I.G., Koutrakis, P., Tsapakis, M., Lagoudaki, E., Stephanou, E.G., Von Baer, D. and Oyola, P. (2001a). Source apportionment of urban particulate aliphatic and polynuclear aromatic hydrocarbons (PAHs) using multivariate methods. Environ. Sci. Technol. 35: 22882294. https://doi.org/10.1021/es001540z

Keskinen, J., Pietarinen, K. and Lehtimäki, M. (1992). Electrical low pressure impactor. J. Aerosol Sci. 23: 353360. https://doi.org/10.1016/0021-8502(92)90004-F

Kim, K.H., Sekiguchi, K., Kudo, S. and Sakamoto, K. (2011). Characteristics of atmospheric elemental carbon (char and soot) in ultrafine and fine particles in a roadside environment, Japan. Aerosol Air Qual. Res. 11: 1-12. https://doi.org/10.4209/aaqr.2010.07.0061

Knoll, G. (2010). Radiation detection and measurement, 4th Edition, 2010, John Wiley \& Sons, Inc.

Koutrakis, P., Sax, S.N., Sarnat, J.A., Coull, B., Demokritou, P., Demokritou, P., Oyola, P., Garcia, J. and Gramsch, E. (2005). Analysis of $\mathrm{PM}_{10}, \mathrm{PM}_{2.5}$, and $\mathrm{PM}_{2.5-10}$ concentrations in Santiago, Chile, from 1989 to 2001. J. Air Waste Manage. Assoc. 55: 342-351. https://doi.org/10.1080/104 73289.2005.10464627

Kulmala, M., Vehkamäki, H., Petäjä, T., DalMaso, M., Lauri, A., Kerminen, V.M., Birmili,W. and MacMurry, P.H., (2004). Formation and growth rates of ultrafine atmospheric particles: A review of observations. Aerosol Sci. 35: 143-176. https://doi.org/10.1016/j.jaerosci.2003. 10.003

Kumar, P., Morawska, L., Birmili, W., Paasonen, P., Hu, M., Kulmala, M., Harrison, R. M., Norford, L. and Britter, R. (2014). Ultrafine particles in cities. Environ. Int. 66: 110. https://doi.org/10.1016/j.envint.2014.01.013
Lin, G.Y., Lee, G.R., Lin, S.F., Hung, Y.H., Li, S.W., Wu, G.J., Ye, H., Huang, W. and Tsai, C.J. (2015). Ultrafine particles and $\mathrm{PM}_{2.5}$ at three urban air monitoring stations in northern Taiwan from 2011 to 2013. Aerosol Air Qual. Res. 15: 2305-2319. https://doi.org/10.4209/aaqr.2015.0 4.0271

Marjamäki, M., Keskinen, J., Chen, D.R. and Pui, D.Y.H. (1999). Performance evaluation of the electrical lowpressure impactor (ELPI). J. Aerosol Sci. 31: 249-261. https://doi.org/10.1016/S0021-8502(99)00052-X

McGraw, R. and Zhang, R. (2008). Multivariate analysis of homogeneous nucleation rate measurements. Nucleation in the $p$-toluic acid/sulfuric acid/water system. J. Chem. Phys. 128: 064508. https://doi.org/10.1063/1.2830030

McKinlay, A.F. and Diffey, B.L. (1987). A reference action spectrum for ultra-violet induced erythema in human skin. In Human Exposure to ultraviolet radiation: Risks and regulations, Passchler, W.R. and Bosnajakovic, B.F.M. (Eds.), Elsevier, Amsterdam, pp. 83-87.

McMurry, P.H., Woo, K.S., Weber, R., Chen, D.R. and Pui, P.Y.H. (2000). Size distributions of 3-10 $\mathrm{nm}$ atmospheric particles: Implications for nucleation mechanisms. Philos. Trans. R. Soc. A 358: 1-18. https://doi.org/10.109 8/rsta.2000.0673

Moreno, F., Gramsch, E., Oyola, P. and Rubio, M.A. (2010). Modification in the soil and traffic-related sources of particle matter between 1998 and 2007 in Santiago de Chile. J. Air Waste Manage. Assoc. 60: 1410-1421. https://doi.org/10.3155/1047-3289.60.12.1410

Muñoz, R. and Corral, M. (2017). Surface indices of wind, stability, and turbulence at a highly polluted urban site in Santiago, Chile, and their relationship with nocturnal particulate matter concentrations. Aerosol Air Qual. Res. 17: 2780-2790. https://doi.org/10.4209/aaqr.2017.05.0190

Németh, Z., Rosati, B., Zíková, N., Salma, I., Bozó, L., Dameto de España, C., Schwarz, J., Ždímal, V. and Wonaschütz, A. (2018). Comparison of atmospheric new particle formation events in three Central European cities. Atmos. Environ. 178: 191-197. https://doi.org/10.1016/j. atmosenv.2018.01.035

Ouf, F.X. and Sillon, P. (2009). Charging efficiency of the electrical low pressure impactor's corona charger: Influence of the fractal morphology of nanoparticle aggregates and uncertainty analysis of experimental results. Aerosol Sci. Technol. 43: 685-698. https://doi.org/10.1080/02786820 902878245

Pérez, P. and Gramsch, E. (2016). Forecasting hourly PM $_{2.5}$ in Santiago de Chile with emphasis on night episodes. Atmos. Environ. 124: 22-27. https://doi.org/10.1016/j.at mosenv.2015.11.016

Salma, I., Borsós, T., Németh, Z., Weidinger, T., Aalto, P. and Kulmala, M. (2014). Comparative study of ultrafine atmospheric aerosol within a city. Atmos. Environ. 92: 145-161. https://doi.org/10.1016/j.atmosenv.2014.04.020

Salma, I., Varga, V. and Németh, Z. (2017). Quantification of an atmospheric nucleation and growth process as a single source of aerosol particles in a city. Atmos. Chem. Phys. 17: 15007-15017. https://doi.org/10.5194/acp-1715007-2017 
Sax, S.N., Koutrakis, P., Rudolph, P.A.R., Cereceda-Balic, F., Gramsch, E. and Oyola, P. (2007). Trends in the elemental composition of fine particulate matter in Santiago, Chile, from 1998 to 2003. J. Air Waste Manage. Assoc. 57: 845855. https://doi.org/10.3155/1047-3289.57.7.845

Seinfeld, J.H., and Pandis, S.N. (2006). Atmospheric chemistry and physics-From air pollution to climate change, 2nd ed. John Wiley \& Sons.

Sorribas, M., Adame, J.A., Olmo, F.J., Vilaplana, J.M., GilOjeda, M. and Alados-Arboledas, L. (2015). A long-term study of new particle formation in a coastal environment: Meteorology, gas phase and solar radiation implications. Sci. Total Environ. 511: 723-737. https://doi.org/10.1016/ j.scitotenv.2014.12.011

Toro, R.A., Morales S., R.G.E., Canales, M., GonzalezRojas, C. and Leiva G., M.A. (2014). Inhaled and inspired particulates in Metropolitan Santiago Chile exceed air quality standards. Build. Environ. 79: 115-123. https://doi.org/10.1016/j.buildenv.2014.05.004

Wahlin, P., Palmgren, F. and Van Dingenen, R. (2001). Experimental studies of ultrafine particles in streets and the relationship to traffic. Atmos. Environ. 35: S63-S69. https://doi.org/10.1016/S1352-2310(00)00500-8
Wiedensohler, A., Wiesner, A., Weinhold, K., Birmili, W., Hermann, M., Merkel, M., Müller, T., Pfeifer, S., Schmidt, A., Tuch, T., Velarde, F., Quincey, P., Seeger, S. and Nowak, A. (2018). Mobility particle size spectrometers: Calibration procedures and measurement uncertainties. Aerosol Sci. Technol. 52: 146-164. https://doi.org/10.108 0/02786826.2017.1387229

Yue, D.L., Hu, M., Zhang, R.Y., Wang, Z.B., Zheng, J., Wu, Z.J., Wiedensohler, A., He, L.Y., Huang, X.F. and Zhu, T. (2010). The roles of sulfuric acid in new particle formation and growth in the mega-city of Beijing. Atmos. Chem. Phys. 10: 4953-4960. https://doi.org/10.5194/acp10-4953-2010

Zhang, R., Khalizov, A., Wang, L., Hu, M. and Xu, W. (2012). Nucleation and Growth of Nanoparticles in the Atmosphere. Chem. Rev. 112: 1957-2011. https://doi.org/ $10.1021 / \mathrm{cr} 2001756$

Received for review, November 2, 2018

Revised, April 22, 2020

Accepted, July 12, 2020 